\title{
Efficacy of Cognitive Remediation in Schizophrenia: A Short Review of Its Variable Effects According to Cognitive Domain
}

\author{
Akihiko Katsumi1 ${ }^{1}$, Hiroshi Hoshino ${ }^{2}$, Satoshi Fujimoto ${ }^{2}$, Shin-Ichi Niwa ${ }^{3 *}$ \\ ${ }^{1}$ Katsumi Clinic, Niigata, Japan \\ ${ }^{2}$ Department of Neuropsychiatry, School of Medicine, Fukushima Medical University, Fukushima, Japan \\ ${ }^{3}$ Department of Psychiatry, Aizu Medical Center, Fukushima Medical University, Fukushima, Japan \\ Email: ${ }^{*}$ si-niwa@fmu.ac.jp
}

Received 3 March 2015; accepted 26 March 2015; published 30 March 2015

Copyright (C) 2015 by authors and Scientific Research Publishing Inc.

This work is licensed under the Creative Commons Attribution International License (CC BY). http://creativecommons.org/licenses/by/4.0/

C) (i) Open Access

\begin{abstract}
Cognitive impairment is a symptom of schizophrenia and strongly associated with impaired social function. In recent years, cognitive interventions (cognitive remediation therapies) have been implemented and their results have also been reported. Intervention studies have been conducted using a variety of methods that differ in terms of terminology, approach, and targeted cognitive domains. In this study, we examined trends in recent cognitive remediation research conducted subsequent to the meta-analyses of McGurk et al. (2007) and Wykes et al. (2011). We identified studies conducted between 2009 and 2013 to examine computer-assisted cognitive remediation and collated and analyzed the literature describing their major results and trends. Our results indicated improved cognitive performance subsequent to cognitive remediation therapy using computer programs. We found promising outcomes, particularly in reasoning and problem solving, verbal learning and memory, verbal working memory, and attention and vigilance, which replicated the findings of Wykes et al. (2011).
\end{abstract}

\section{Keywords}

Schizophrenia, Cognitive Deficit, Cognitive Remediation, Variance, Cognitive Domain

\section{Introduction}

Relative to the positive and negative symptoms of schizophrenia, the cognitive deficits associated with the con-

"Corresponding author.

How to cite this paper: Katsumi, A., Hoshino, H., Fujimoto, S. and Niwa, S.-I. (2015) Efficacy of Cognitive Remediation in Schizophrenia: A Short Review of its Variable Effects According to Cognitive Domain. Open Journal of Psychiatry, 5, $170-176$. http://dx.doi.org/10.4236/ojpsych.2015.52019 
dition have a stronger relationship with social outcomes in daily life, including those involving work and school [1]. In recent years, cognitive interventions (cognitive remediation therapies) have been implemented and their results reported. As a means of improving participants' daily functioning, numerous interventions have been designed to improve multiple cognitive domains, and the number of papers reporting related randomized controlled trials (RCTs) has also increased [2] [3].

Intervention studies have been conducted using a variety of methods that differ in terms of terminology, approach, and targeted cognitive domains. Some focus on specific cognitive functions, such as attention [4] [5] and executive processing [6], while others target a range of these functions simultaneously [7] or examine social cognition [8] [9]. In addition, there are now integrative programs that pair cognitive remediation with activities such as social skills training [10].

Several papers have reviewed the degree to which cognitive remediation therapy improves cognition. Overall, these reviews have shown a medium effect size. McGurk et al. [11] performed a meta-analysis of 26 RCTs, calculated effect sizes across various outcomes, and reported effect sizes of $0.41,0.36$, and 0.28 for cognitive performance, psychosocial functioning, and symptoms, respectively. Wykes et al. [12] investigated the effects of cognitive remediation in a meta-analysis of 40 studies and reported a medium effect size of 0.45 for improved cognition and a very similar effect size of 0.42 for improved functioning. They also reported that the effect of cognitive remediation therapy on function was significantly larger when it was carried out in conjunction with other types of psychiatric rehabilitation. Cognitive remediation is used with increasing frequency as a therapeutic intervention intended to improve social function, employment, and quality of life [13]-[15]. Medalia and Saperstein [16] summarized studies published since 2011, with a focus on improvement of social function. They concluded that "cognitive remediation is most likely to impact functional outcome when individuals are given opportunities to practice the cognitive skills in real-world settings". In this study, we summarized the cognitive outcomes reported in cognitive remediation research conducted subsequent to the reviews of McGurk et al. [11] and Wykes et al. [12]. Further, while referring to these reviews, we aimed to determine whether outcomes varied consistently according to cognitive domain in the existing research and how their effect size should be judged.

\section{Summary of Recent Findings in Cognitive Remediation Therapy Research}

In this study, we examined trends in recent cognitive remediation research conducted subsequent to the metaanalyses of McGurk et al. [11] and Wykes et al. [12]. While there are many types of cognitive remediation therapy, no reviews focusing exclusively on the effectiveness of computer-assisted cognitive remediation have been conducted thus far. Therefore, we identified studies conducted between 2009 and 2013 to examine computer-assisted cognitive remediation and analyzed the literature describing their major results and trends.

\section{Methods}

\subsection{Literature Sampling}

We performed our literature search using the PubMed online database. We initially searched for literature containing all of our search terms, which were "cognitive," "remediation” or "enhancement" or "rehabilitation," "training" or "therapy," and "schizophrenia." We then reduced the results to those that met the following criteria: 1) the training made use of computers; 2) at least one cognitive domain was measured both pre- and postintervention; and 3) a randomized controlled trial was conducted. Sixteen publications met these criteria [2] [16]-[30]. We then examined the cognitive outcomes described for these 16 studies.

\subsection{Methods of Evaluating Efficacy and Effect Size}

We used a 16-study sample to verify cognitive efficacy. Cognitive domains were categorized according to the grouping described by the Measurement and Treatment Research to Improve Cognition in Schizophrenia consensus panel: 1) attention/vigilance; 2) speed of processing; 3) verbal working memory; 4) verbal learning and memory; 5) visual learning and memory; 6) reasoning/problem solving; and 7) social cognition. Nonverbal working memory was only addressed by one of the 16 studies and was therefore omitted.

We examined the efficacy of cognitive remediation therapy in each of the seven cognitive domains described above, according to three criteria: 1 ) six or more studies examined the domain (1/3 or more of the 16 -study sam- 
ple); 2) at least half of the studies reported significant improvement; and 3) the median effect size was 0.3 or larger. On the basis of these criteria, we classified the effects of cognitive remediation therapy into one the following four categories: Category A: "effective," in which all three criteria were met; Category B: "likely effective," in which two of the three criteria were met; Category C: "possibly effective," in which one of the three criteria were met; And Category D: "cannot claim efficacy," in which none of the three criteria were met. The efficacy of cognitive remediation for each domain was evaluated according to these categories. It should be noted that some studies found significant improvements but did not report effect sizes; therefore, median effect sizes were calculated using the studies for which they were reported [2] [17] [18] [27] [30]. If the only literature available for a particular domain did not report effect sizes, the domain was considered to have failed Criterion 3 ("the median effect size was 0.3 or larger").

\section{Results}

Using the methods described above, we tabulated the efficacy and effect sizes of computer-assisted cognitive remediation for each cognitive domain, with the following results (see Table 1).

1) Attention/vigilance: 12 of the 16 studies [2] [17] [18] [20] [21] [23]-[28] [30] assessed this domain, seven of which [2] [17] [23] [25]-[28] reported significant improvement. The median effect size recorded in the literature was 0.50 (0.35 - 0.65); therefore, we assigned this domain to Category A: "effective."

2) Speed of processing: 13 of the 16 studies [2] [18]-[27] [30] [31] assessed this domain, four of which [22] [23] [27] [30] reported significant improvement. The median effect size recorded in the literature was 0.30; therefore, we assigned this domain to Category B: "likely effective."

3) Verbal working memory: 14 of the 16 studies [17]-[30] assessed this domain, eight of which [18] [23] [25]-[30] reported significant improvement. The median effect size recorded in the literature was 0.51 (0.44 0.58); therefore, we assigned this domain to Category A: "effective."

(4) Verbal learning and memory: 15 of the 16 studies [2] [17]-[19] [21]-[31] assessed this domain, nine of which [2] [18] [19] [21] [23] [24] [27] [28] [31] reported significant improvement. The median effect size recorded in the literature was 0.66 (0.18 - 1.13); therefore, we assigned this domain to Category A: "effective."

(5) Visual learning and memory: 6 of the 16 studies [2] [19] [23] [25]-[27] assessed this domain, three of which [2] [23] [27] reported significant improvement. The median effect size recorded in the literature was 0.26; therefore, we assigned this domain to Category B: "likely effective."

(6) Reasoning/problem solving: 14 of the 16 studies [2] [17]-[25] [27] [28] [30] [31] assessed this domain, 10 of which [2] [17]-[19] [23] [24] [27] [28] [30] [31] reported significant improvement. The median effect size recorded in the literature was 0.79 (0.28 - 1.29); therefore, we assigned this domain to Category A: "effective."

(7) Social cognition: 2 of the 16 studies [18] [19] assessed this domain, one of which [18] reported significant improvement. However, because effect size was not recorded in the literature, this domain was considered to have failed Criterion 3; therefore, we assigned the domain to Category C: "possibly effective."

\section{Discussion}

As shown above, of the seven cognitive domains considered, attention/vigilance, verbal working memory, verbal learning and memory, and reasoning/problem solving were assigned to Category A (effective). Category B (likely effective) contained the speed of processing and visual learning and memory domains, and Category C (possibly effective) contained the social cognition domain. No domains were assigned to Category D (cannot claim efficacy). We can therefore conclude that effects were demonstrated for intervention across all seven cognitive domains.

These results are very similar to those of the meta-analysis conducted by Wykes et al. [12]; however, while meta-analysis showed strong improvement in social cognition, our trend analysis only found possible efficacy for this domain.

We theorized that this may have occurred as so few studies in our review measured social cognition. Our results also showed somewhat larger effect sizes than those reported by Wykes et al. [12] across all domains. The effect sizes in our study were calculated solely from the medians of those reported for the studies that measured effect size, and served as nothing more than reference values. However, the present study specifically considered research examining computer-assisted cognitive remediation, and these results suggested that computer- 
Table 1. Study of the effect size of cognitive function domain.

\begin{tabular}{|c|c|c|c|c|c|c|c|}
\hline \multirow{2}{*}{ Reference } & \multicolumn{2}{|l|}{$\begin{array}{l}\text { Sample } \\
\text { size }\end{array}$} & \multirow{2}{*}{$\begin{array}{l}\text { Mean } \\
\text { age } \\
\text { (years) }\end{array}$} & \multirow{2}{*}{$\begin{array}{l}\text { Duration } \\
\text { (weeks) }\end{array}$} & \multirow{2}{*}{$\begin{array}{l}\text { Weekly } \\
\text { frequency }\end{array}$} & \multirow{2}{*}{$\begin{array}{l}\text { Cognitive domains with } \\
\text { significant improvement after } \\
\text { remediation domains } \\
\text { (effect size) }\end{array}$} & \multirow{2}{*}{ Assessed cognitive domains } \\
\hline & Experimental & Control & & & & & \\
\hline $\begin{array}{l}\text { Cavallaro } \\
\text { et al. } \\
\text { (2009) [17] }\end{array}$ & 31 & 27 & 25.9 & 100 & 1 & $\begin{array}{l}\text { verbal memory (effect size not } \\
\text { available), executive function } \\
\text { (effect size not available), } \\
\text { social cognition (effect size } \\
\text { not available) }\end{array}$ & $\begin{array}{l}\text { speed of processing, attention, } \\
\text { verbal and working memory, } \\
\text { executive function, social cognition }\end{array}$ \\
\hline $\begin{array}{l}\text { Eack et al. } \\
\text { (2009) [18] }\end{array}$ & 29 & 26 & 44.1 & 10 & 5 & $\begin{array}{c}\text { verbal learning }(0.86) \text {, verbal } \\
\text { memory }(0.89) \text {, verbal working } \\
\text { memory }(0.58), \text { problem } \\
\text { solving }(0.55)\end{array}$ & $\begin{array}{c}\text { speed of processing, verbal } \\
\text { working memory, verbal learning, } \\
\text { verbal memory, problem solving, } \\
\text { nonverbal working memory, visual } \\
\text { learning, visual memory, social } \\
\text { cognition }\end{array}$ \\
\hline $\begin{array}{l}\text { Fisher et al. } \\
\text { (2009) [19] }\end{array}$ & 50 & 36 & 33.7 & 12 & 3 & $\begin{array}{l}\text { executive function }(0.56) \text { and } \\
\text { attention performances }(0.53)\end{array}$ & $\begin{array}{l}\text { verbal memory, working } \\
\text { memory, letter fluency, } \\
\text { semantic fluency, planning, } \\
\text { attention, executive function }\end{array}$ \\
\hline $\begin{array}{l}\text { Dickinson } \\
\text { et al. } \\
\text { (2010) [20] }\end{array}$ & 34 & 27 & 47.7 & 15 & 3 & no significant improvement & $\begin{array}{l}\text { attention, working memory, } \\
\text { episodic memory, processing } \\
\text { speed, executive function }\end{array}$ \\
\hline $\begin{array}{l}\text { Fisher et al. } \\
\text { (2010) [21] }\end{array}$ & 22 & 10 & 36.4 & 50 & 1 & $\begin{array}{l}\text { verbal learning/memory } \\
\text { (effect size not available) }\end{array}$ & $\begin{array}{l}\text { attention, working memory, speed } \\
\text { of processing, verbal } \\
\text { learning/memory, problem solving }\end{array}$ \\
\hline $\begin{array}{l}\text { Hodge et al. } \\
\text { (2010) [2] }\end{array}$ & 36 & 33 & 31.3 & 15 & 2 & $\begin{array}{l}\text { verbal memory }(0.18) \text {, visual } \\
\text { memory }(0.26) \text {, attention }(0.65) \text {, } \\
\text { executive function }(0.28)\end{array}$ & $\begin{array}{l}\text { processing speed, executive } \\
\text { function, attention, verbal learning, } \\
\text { verbal and visual memory, }\end{array}$ \\
\hline $\begin{array}{l}\text { Vita et al. } \\
\text { (2011) [22] }\end{array}$ & 30 & 28 & 39.9 & 24 & 2 & $\begin{array}{c}\text { speed of processing } \\
\text { (effect size not available) }\end{array}$ & $\begin{array}{c}\text { speed of processing, working } \\
\text { memory, verbal memory, } \\
\text { executive function, composite score }\end{array}$ \\
\hline $\begin{array}{l}\text { Gharaeipour } \\
\text { et al. (2012) } \\
\text { [23] }\end{array}$ & 21 & 21 & 22.24 & 8 & 5 & $\begin{array}{l}\text { verbal working memory (effect } \\
\text { size not available),visual learning } \\
\text { and memory (effect size not } \\
\text { available), attention(effect size } \\
\text { not available), processing } \\
\text { speed(effect size not available), } \\
\text { executive function(effect size } \\
\text { not available) }\end{array}$ & $\begin{array}{l}\text { verbal learning, verbal memory, } \\
\text { executive function, verbal } \\
\text { working memory, visual learning } \\
\text { and memory, attention, } \\
\text { processing speed }\end{array}$ \\
\hline $\begin{array}{c}\text { Ikezawa } \\
\text { et al. }(2012) \\
{[24]}\end{array}$ & 26 & 25 & 38.5 & 24 & 2 & $\begin{array}{l}\text { verbal memory (effect size not } \\
\text { available), working memory } \\
\text { (effect size not available), } \\
\text { verbal fluency (effect size not } \\
\text { available), attention (effect size } \\
\text { not available), executive function } \\
\text { (effect size not available) }\end{array}$ & $\begin{array}{c}\text { verbal memory, working } \\
\text { memory, verbal fluency, } \\
\text { attention/processing speed, } \\
\text { executive function }\end{array}$ \\
\hline $\begin{array}{l}\text { Rass et al. } \\
\text { (2012) [25] }\end{array}$ & 17 & 27 & 42.2 & 10 & 2 & no significant improvement & $\begin{array}{l}\text { verbal memory, visual working } \\
\text { memory, non-verbal memory, } \\
\text { processing speed, working } \\
\text { memory, attention, letter and } \\
\text { category fluency }\end{array}$ \\
\hline $\begin{array}{c}\text { D’Souza } \\
\text { et al. }(2013) \\
{[26]}\end{array}$ & 27 & 26 & 39.9 & 12 & 2 & $\begin{array}{l}\text { verbal working memory } \\
\text { (effect size not available) }\end{array}$ & $\begin{array}{l}\text { speed of processing, verbal working } \\
\text { memory, visual working memory, } \\
\text { memory, executive function }\end{array}$ \\
\hline
\end{tabular}




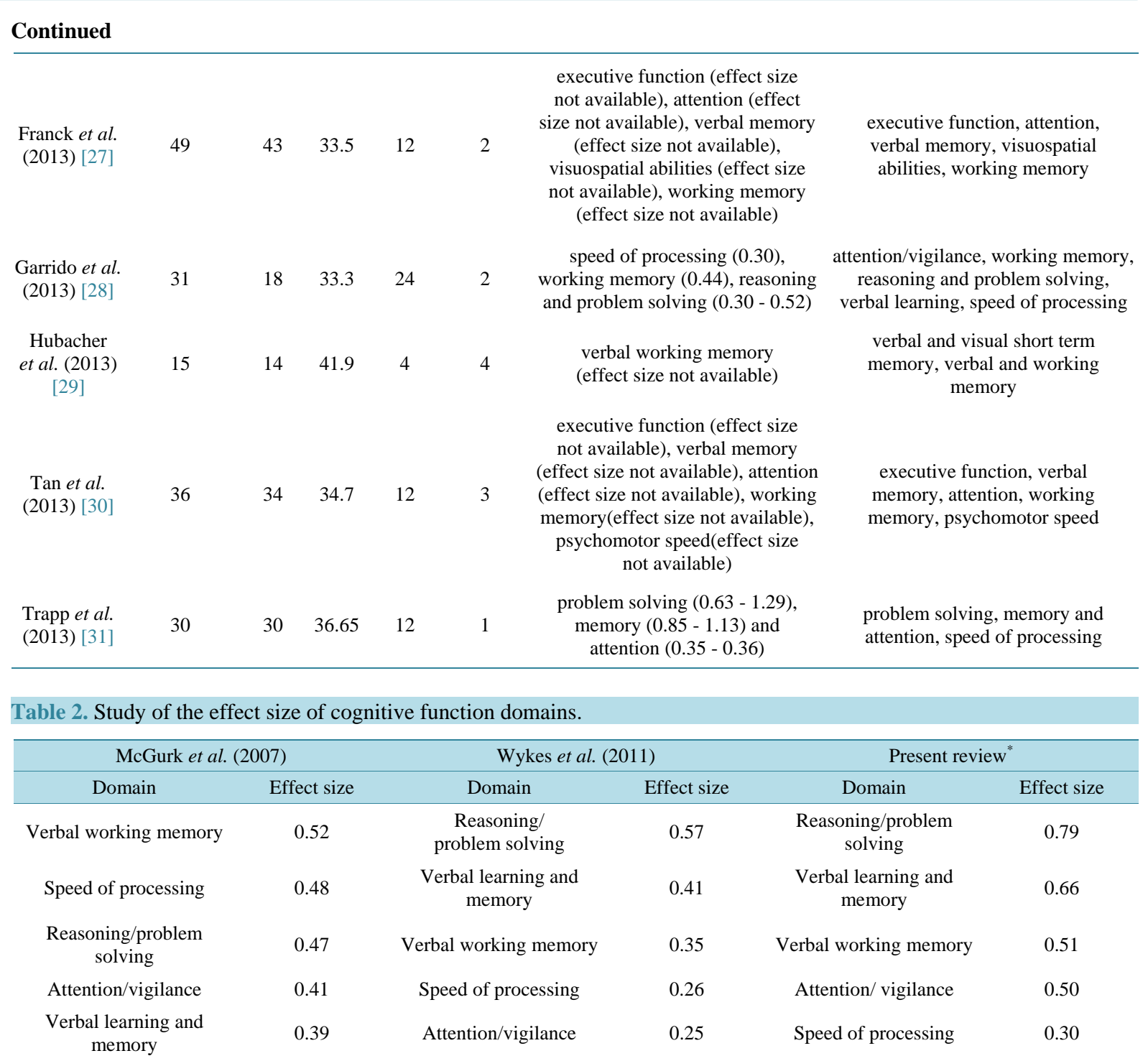

*Summarizes the article on cognitive remediation for 2009-2013.

assisted cognitive remediation may be more effective relative to the various other types of remediation.

Comparing the degrees of improvement in the different domains, the largest effect size in our review was that of reasoning/problem solving (ES 0.79), followed by those of verbal learning and memory (ES 0.66), verbal working memory (ES 0.51), attention/vigilance (ES 0.50), and speed of processing (ES 0.30). In Wykes et al.'s meta-analysis [12], the largest effect size was that of reasoning/problem solving (ES 0.572), followed by those of verbal learning and memory (ES 0.410), verbal working memory (ES 0.346), speed of processing (ES 0.258), and attention/vigilance (ES 0.250). Further, in McGurk et al.'s meta-analysis [11], the largest effect size was that of verbal working memory (ES 0.52), followed by those of speed of processing (ES 0.48), reasoning/problem solving (ES 0.47), attention/vigilance (ES 0.41), and verbal learning and memory (ES 0.39; see Table 2). In McGurk et al.'s review [11], outcomes were similar across all cognitive domains. In contrast, our review and that conducted by Wykes et al. [12] found great improvement in the reasoning/problem solving, verbal learning and memory, and verbal working memory domains, while the effect sizes for attention/vigilance and speed of processing indicated small improvement. In our review and the meta-analysis conducted by Wykes et al. [12], the research results analyzed were more recent relative to those considered by McGurk et al. [11] and should reflect the efficacy of computer-assisted cognitive remediation more clearly. In short, our results showed improved cognitive performance subsequent to cognitive remediation therapy using computer programs, with 
particularly promising outcomes for reasoning/problem solving, verbal learning and memory, verbal working memory, and attention/vigilance.

\section{References}

[1] Heinrichs, R.W. (2004) Meta-Analysis and the Science of Schizophrenia: Variant Evidence or Evidence of Variants? Neuroscience \& Biobehavioral Review, 28, 379-394. http://dx.doi.org/10.1016/j.neubiorev.2004.06.003

[2] Hodge, M.A., Siciliano, D., Witney, P., Moss, B., Moore, C., Judd, G., et al. (2010) A Randomized Controlled Trial of Cognitive Remediation in Schizophrenia. Schizophrenia Bulletin, 36, 419-427. http://dx.doi.org/10.1093/schbul/sbn102

[3] d’Amato, T., Bation, R., Cochet, A., Jalenques, I., Galland, F., Giraud-Baro, E., et al. (2011) A Randomized, Controlled Trial of Computer-Assisted Cognitive Remediation for Schizophrenia. Schizophrenia Research, 125, $284-290$. http://dx.doi.org/10.1016/j.schres.2010.10.023

[4] Benedict. R.H., Harris, A.E., Markow, T., McCormick, J.A., Nuechteriein, K.H. and Asarnow, R.F. (1994) Effects of Attention Training on Information Processing in Schizophrenia. Schizophrenia Bulletin, 20, 537-546. http://dx.doi.org/10.1093/schbul/20.3.537

[5] Lopez-Luengo, B. and Vazquez, C. (2003) Effects of Attention Process Training on Cognitive Functioning of Schizophrenic Patients. Psychiatry Research, 119, 41-53. http://dx.doi.org/10.1016/S0165-1781(03)00102-1

[6] Wykes, T., Reeder, C., Corner, J., Williams, C. and Everitt, B. (1999) The Effects of Neurocognitive Remediation on Executive Processing in Patients with Schizophrenia. Schizophrenia Bulletin, 25, 291-307. http://dx.doi.org/10.1093/oxfordjournals.schbul.a033379

[7] Bellucci, D.M., Glaberman, K. and Hasiam, N. (2003) Computer-Assisted Cognitive Rehabilitation Reduces Negative Symptoms in The Severely Mentally Ill. Schizophrenia Research, 59, 225-232. http://dx.doi.org/10.1016/S0920-9964(01)00402-9

[8] van der Gaag, M., Kern, R.S., van den Bosch, R.J. and Liberman, R.P. (2002) A Controlled Trial of Cognitive Remediation in Schizophrenia. Schizophrenia Bulletin, 28, 167-176. http://dx.doi.org/10.1093/oxfordjournals.schbul.a006919

[9] Wolwer, W., Frommann, N., Halfmann, S., Piaszek, A., Streit, M. and Gaebel, W. (2005) Remediation of Impairments in Facial Affect Recognition in Schizophrenia: Efficacy and Specificity of A New Training Program. Schizophrenia Research, 80, 295-303. http://dx.doi.org/10.1016/j.schres.2005.07.018

[10] Medalia, A., Revheim, N. and Casey, M. (2001) The Remediation of Problem-Solving Skills in Schizophrenia. Schizophrenia Bulletin, 27, 259-267. http://dx.doi.org/10.1093/oxfordjournals.schbul.a006872

[11] McGurk, S.R., Twamley, E.W., Sitzer, D.I., McHugo, G.J. and Mueser, K.T. (2007) A Meta-Analysis of Cognitive Remediation in Schizophrenia. American Journal of Psychiatry, 164, 1791-1802. http://dx.doi.org/10.1176/appi.ajp.2007.07060906

[12] Wykes, T., Huddy, V., Cellard, C., McGurk, S.R. and Czobor, P.A. (2011) A Meta-Analysis of Cognitive Remediation for Schizophrenia: Methodology and Effect Sizes. American Journal of Psychiatry, 168, 472-485. http://dx.doi.org/10.1176/appi.ajp.2010.10060855

[13] Bell, M.D., Zito, W. and Greig, T. (2008) Neurocognitive Enhancement Therapy with Vocational Services: Work Outcomes at Two-Year Follow-Up. Schizophrenia Research, 105, 18-29. http://dx.doi.org/10.1016/j.schres.2008.06.026

[14] McGurk, S.R., Mueser, K.T. and Pascaris, A. (2005) Cognitive Training and Supported Employment for Persons with Severe Mental Illness: One Year Results from a Randomized Controlled Trial. Schizophrenia Bulletin, 31, 898-909. http://dx.doi.org/10.1093/schbul/sbi037

[15] Vauth, R., Corrigan, P.W., Clauss, M., Dietl, M., Dreher-Rudolph, M., Stieglitz, R.-D., et al. (2005) Cognitive Strategies versus Self-Management Skills as Adjunct to Vocational Rehabilitation. Schizophrenia Bulletin, 31, 55-66. http://dx.doi.org/10.1093/schbul/sbi013

[16] Medalia, A. and Saperstein, A.M. (2013) Does Cognitive Remediation for Schizophrenia Improve Functional Outcomes? Current Opinion in Psychiatry, 26, 151-157. http://dx.doi.org/10.1097/YCO.0b013e32835dcbd4

[17] Cavallaro, R., Anselmetti, S., Poletti, S., Dietl, M., Dreher-Rudolph, M., Stieglitz, R.-D. and Vater, R. (2009) ComputerAided Neurocognitive Remediation as an Enhancing Strategy for Schizophrenia Rehabilitation. Psychiatry Research, 169, 191-196. http://dx.doi.org/10.1016/j.psychres.2008.06.027

[18] Eack, S.M., Greenwald, D.P., Hogarty, S.S., Cooley, S.J., DiBarry, A.L., Montrose, D.M. and Keshavan, M.S. (2009) Cognitive Enhancement Therapy for Early-Course Schizophrenia: Effects of a Two-Year Randomized Controlled Trial. Psychiatric Services, 60, 1468-1476. http://dx.doi.org/10.1176/ps.2009.60.11.1468

[19] Fisher, M., Holland, C., Merzenich, M.M. and Vinogradov, S. (2009) Using Neuroplasticity-Based Auditory Training to Improve Verbal Memory in Schizophrenia. American Journal of Psychiatry, 166, 805-811. 
http://dx.doi.org/10.1176/appi.ajp.2009.08050757

[20] Dickinson, D., Tenhula, W., Morris, S., Brown, C., Peer, J., Spencer, K., et al. (2010) A Randomized, Controlled Trial of Computer-Assisted Cognitive Remediation for Schizophrenia. American Journal of Psychiatry, 167, 170-180. http://dx.doi.org/10.1176/appi.ajp.2009.09020264

[21] Fisher, M., Holland, C., Subramaniam, K. and Vinogradov, S. (2010) Neuroplasticity-Based Cognitive Training in Schizophrenia: An Interim Report on the Effects 6 Months Later. Schizophrenia Bulletin, 36, 869-879. http://dx.doi.org/10.1093/schbul/sbn170

[22] Vita, A., De Peri, L., Barlati, S., Cacciani, P., Deste, G., Poli, R., et al. (2011) Effectiveness of Different Modalities of Cognitive Remediation on Symptomatological, Neuropsychological, and Functional Outcome Domains in Schizophrenia: A Prospective Study in a Real-World Setting. Schizophrenia Research, 133, 223-231.

http://dx.doi.org/10.1016/j.schres.2011.08.010

[23] Gharaeipour, M. and Scott, B.J. (2012) Effects of Cognitive Remediation on Neurocognitive Functions and Psychiatric Symptoms in Schizophrenia Inpatients. Schizophrenia Research, 142, 165-170. http://dx.doi.org/10.1016/j.schres.2012.09.018

[24] Ikezawa, S., Mogami, T., Hayami, Y., Sato, I., Kato, T., Kimura, I., et al. (2012) The Pilot Study of A Neuropsychological Educational Approach to Cognitive Remediation for Patients with Schizophrenia in Japan. Psychiatry Research, 195, 107-110. http://dx.doi.org/10.1016/j.psychres.2011.07.020

[25] Rass, O., Forsyth, J.K., Bolbecker, A.R., Hetrick, W.P., Breier, A., Lysaker, P.H., O’Donnell, B.F., et al. (2012) Computer-Assisted Cognitive Remediation for Schizophrenia: A Randomized Single-Blind Pilot Study. Schizophrenia Research, 139, 92-98. http://dx.doi.org/10.1016/j.schres.2012.05.016

[26] D’Souza, D.C., Radhakrishnan, R., Perry, E., Bhakta, S., Singh, N.M., Yadav, R., et al. (2013) Feasibility, Safety, and Efficacy of the Combination of D-serine and Computerized Cognitive Retraining in Schizophrenia: An International Collaborative Pilot Study. Neuropsychopharmacology, 38, 492-503. http://dx.doi.org/10.1038/npp.2012.208

[27] Franck, N., Duboc, C., Sundby, C., Amado, I., Wykes, T., Demily, C., et al. (2013) Specific vs. General Cognitive Remediation for Executive Functioning in Schizophrenia: A Multicenter Randomized Trial. Schizophrenia Research, 147, 68-74. http://dx.doi.org/10.1016/j.schres.2013.03.009

[28] Garrido, G., Barrios, M., Penadés, R., Enríquez, M., Garolera, M., Aragay, N., et al. (2013) Computer-Assisted Cognitive Remediation Therapy: Cognition, Self-Esteem and Quality of Life in Schizophrenia. Schizophrenia Research, 150, 563-569. http://dx.doi.org/10.1016/j.schres.2013.08.025

[29] Hubacher, M., Weiland, M., Calabrese, P., Stoppe, G., Stöcklin, M., Fischer-Barnicol, D., et al. (2013) Working Memory Training in Patients with Chronic Schizophrenia: A Pilot Study. Psychiatry Journal, 2013, Article ID: 154867.

[30] Tan, B.L. and King, R. (2013) The Effects of Cognitive Remediation on Functional Outcomes Among People with Schizophrenia: A Randomised Controlled Study. Australian \& New Zealand Journal of Psychiatry, 47, 1068-1080. http://dx.doi.org/10.1177/0004867413493521

[31] Trapp, W., Landgrebe, M., Hoesl, K., Lautenbacher, S., Gallhofer, B., Günther, W. and Hajak, G. (2013) Cognitive Remediation Improves Cognition and Good Cognitive Performance Increases Time to Relapse-Results of a 5 Year Catamnestic Study in Schizophrenia Patients. BMC Psychiatry, 13, 184. http://dx.doi.org/10.1186/1471-244X-13-184 